\title{
TOX3 (TNRC9) Overexpression in Bladder Cancer Cells Decreases Cellular Proliferation and Triggers an Interferon-Like Response
}

Karin Birkenkamp-Demtroder ${ }^{1 *}$, Francisco Mansilla1 ${ }^{1}$, Lars Dyrskjøt ${ }^{1}$, Kasper Thorsen ${ }^{1}$, Niels Fristrup ${ }^{1}$, Anne Sofie Brems-Eskildsen ${ }^{1}$, Pia Pinholt Munksgaard ${ }^{1}$, Karina Dalsgaard Sørensen ${ }^{1}$, Michael Borre ${ }^{2}$ and Torben Falck Ørntoft ${ }^{1}$

${ }^{1}$ Department of Molecular Medicine (MOMA), Aarhus University Hospital, Skejby, Denmark

${ }^{2}$ Department of Urology, Aarhus University Hospital, Skejby, Denmark

\begin{abstract}
Background: Human TOX3 (TOX high mobility group box family member 3 ) regulates $\mathrm{Ca}^{2+}$ dependent transcription in neurons and has been associated with breast cancer susceptibility. Aim of the study was to investigate the expression of TOX3 in bladder cancer tissue samples and to identify genes and pathways altered upon TOX3 dysregulation using a cell line model.

Methods: We performed microarray transcript profiling of biopsies and validated the data with RT-qPCR. We used cell line models for Overexpression and siRNA mediated knockdown of TOX3. Pathway analysis was applied for target gene identification and immunoprecipitation studies were used for DNA binding studies.

Results: Microarray transcript profiling of 89 bladder biopsies showed a significant up-regulation of TOX3 $\left(p<10^{-4}\right)$ in non-muscle invasive (Ta-T1) bladder tumors compared to muscle-invasive (T2-T4) bladder tumors and normal urothelium. Microarray expression profiling of human bladder cancer cells over expressing TOX 3 followed by Pathway analysis showed that TOX3 Overexpression mainly affected the Interferon Signaling Pathway. TOX3 up regulation induced the expression of several genes with a gamma interferon activation site (GAS), e.g. STAT1. In vitro functional studies showed that TOX3 was able to bind to the GAS-sequence located at the STAT1 promoter. siRNA mediated knockdown of TOX3 in RT4 bladder cancer cells decreased STAT1 expression suggesting a direct impact of TOX3 on STAT1. Immunoprecipitation of TOX3 over expressing cell extracts with an artificial "GAS"DNA element resulted in an enrichment of the GAS containing DNA-sequence, providing evidence for a potential interaction of TOX3 with the GAS-sequence of STAT1.
\end{abstract}

Conclusions: These results provide evidence for an alternative activation of the downstream interferon targets, independent of the initial interferon-receptor interaction, and consequently a biological role for TOX3.

Keywords: Bladder cancer; Transcription factor; Microarray; Interferon pathway; RT4 bladder cancer cells; STAT1; TOX3; Interferon treatment

\section{Introduction}

Urothelial bladder cancer is estimated to be the ninth most common cause of cancer worldwide and the $13^{\text {th }}$ most common cause of death from cancer [1]. The overall cause-specific five-year survival rate is about $65 \%$. Bladder cancer occurs as non-muscle-invasive tumors (stages Ta and T1), muscle-invasive tumors (T2-T4) or carcinoma in situ [2]. Previously, we identified stage-characteristic, functionallyrelated gene expression patterns in samples from non-muscle invasive and muscle invasive human bladder cancers [3], among those TOX3 (TOX high mobility group box family member 3 ), also called TNRC9 (Trinucleotide repeat-containing gene 9 protein) or CAGF9 (CAG trinucleotide repeat-containing gene $\mathrm{F} 9$ protein).

TOX3, located on chromosome 16q12.1, is a member of an evolutionarily conserved DNA-binding protein subfamily of the HMG-box proteins defined by TOX [4]. TOX3 contains three domains: an N-terminal domain with a NLS (Nuclear Localization Signal), a HMG box, indicating that the protein may be involved in bending and unwinding of DNA and alteration of the chromatin structure [4] and a C-terminal polyglutamine stretch [5], suggesting a direct role in transcription.

Single nucleotide polymorphisms (SNPs) in the TOX3 gene have been associated with breast cancer [6-11], but cancer susceptibility varies depending on the populations studied $[12,13]$. Data from SAGE database indicate that TOX3 is generally low expressed or absent in normal tissues of the body, indicating a potential role in processes of the embryonic development. RT-qPCR analyses of human tissues shows a strong expression of TOX 3 in the ileum and in the mammalian brain in the frontal and the occipital lobe, while TOX3 expression was absent in most normal adult tissues including the urothelium [14]. There is increasing evidence that TOX3 may play a role in cancer development $[15,16]$. A recent study on lung cancer showed low TOX3 expression in normal lung tissue while TOX3 was identified to be strongly upregulated in $70 \%$ of the lung adenocarcinomas [16]. In addition to that Tessema et al. [17] recently identified that TOX3 expression is epigenetically regulated and that lung tumors are more frequently methylated than breast tumors [17].

In neuronal rat cells, TOX3 was described as a $\mathrm{Ca}^{2+}$-dependent neuronal transcription factor. TOX3 Overexpression induces anti-

${ }^{*}$ Corresponding author: Karin Birkenkamp-Demtroder, Department of Molecular Medicine (MOMA), Aarhus University Hospital, Skejby, Brenstrupgaardsvej 100 , DK-8200 Aarhus N, Denmark, Tel: +45-78-45-53-71; Fax: +45-8678-2108; E-mail: kbdr@ki.au.dk

Received November 20, 2012; Accepted January 08, 2013; Published January 10, 2013

Citation: Birkenkamp-Demtroder K, Mansilla F, Dyrskjøt L, Thorsen K, Fristrup N, et al. (2013) TOX3 (TNRC9) Overexpression in Bladder Cancer Cells Decreases Cellular Proliferation and Triggers an Interferon-Like Response. J Mol Biomark Diagn 4: 140. doi:10.4172/2155-9929.1000140

Copyright: (c) 2013 Birkenkamp-Demtroder K, et al. This is an open-access article distributed under the terms of the Creative Commons Attribution License, which permits unrestricted use, distribution, and reproduction in any medium, provided the original author and source are credited 
apoptotic transcripts and thus protects neuronal rat cells from cell death [18]. TOX3 interacts with both cAMP response element (CRE)-binding protein (CREB) and CREB-binding protein (CBP), and knockdown of the endogenous TOX3 by siRNA leads to significant reduction of calcium-induced c-fos expression and complete inhibition of calcium activation of the $c$-fos promoter in rat neurons [18]. In lung cancer, TOX3 knockdown targeted neuronal development and function [17]. TOX3 was described as a neuronal survival factor regulating calcium dependent transcription in neurons [14]. In neuronal Neuro2a cells, TOX3 and CITED3 are present in a complex being linked through the HMG domain of TOX3 [14]. In human embryonic kidney cells (HEK293) stably over-expressing the constitutively active receptor GPR39, TOX3 and CITED1 are induced in concert [19]. TOX3 also interacts with native CREB and induces the CREB-responsive BCL-2 promoter, which can be inhibited by co expression of CITED1. In contrast, coexpression of CREB abolishes TOX3-mediated transcription from the estrogen-responsive complement C3 promoter [14].

Moreover, differential expression of TOX3 is suggested to play a role in carcinogenesis as the TOX3 transcript was found to be upregulated in luminal A, luminal B and ErbB2+ breast cancer while down-regulated in basal-like breast cancer subtypes [15]. Moreover, TOX3 expression has been described as part of a 20-gene expression model for prediction of nodal disease risk in bladder cancer patients [20].

To the best of our knowledge, no publication has focused on the expression and functional impact of TOX3 in bladder cancer. The aim of this study was to investigate the expression of TOX3 in human bladder cancer and to identify potential genes and pathways as well as cellular functions altered upon TOX3 dysregulation. Microarray expression profiling of the TOX 3 transcript was performed on a total of 89 bladder cancer biopsies, comprising 9 normal bladder epithelia and 80 bladder tumors. TOX3 was found to be strongly up-regulated in non-muscleinvasive tumors compared to normal urothelium and muscle-invasive tumors. Transient over-expression of TOX 3 in T24 bladder cancer cells decreased cell viability, and genome-wide transcript profiling showed that TOX3 triggered an interferon-like response, thereby increasing e.g. STAT1 expression. The identified relation between TOX3 and STAT1 was supported by siRNA mediated knockdown of TOX3 in RT4 bladder cancer cells which resulted in a decreased expression of STAT1, suggesting a direct impact of TOX3 on STAT1.

\section{Materials and Methods}

\section{Tumor specimens}

Bladder tissue samples were collected prospectively at the Department of Urology at Aarhus University Hospital, Skejby. Informed consent was obtained from all patients involved, and the protocol was approved by the Central Denmark Region Committees on Biomedical Research Ethics (1994/2920). Samples were selected from three studies previously conducted at our department and detailed information of the samples is given in [3,21-23].

In brief, tumor tissue samples were obtained directly from surgery after removal of the necessary amount of tissue for routine pathology examination. Tumors were flash frozen in liquid nitrogen immediately after surgery and stored at $-80^{\circ} \mathrm{C}$. Diagnostic pathology slides were reevaluated by an experienced uropathologist and graded according to the WHO 2004 guidelines [24].

\section{Sample preparation and gene expression}

It was performed on 89 bladder tissue samples, 9 normal urothelia,
52 non-muscle-invasive Ta tumors, $4 \mathrm{~T} 1$ tumors and 24 muscleinvasive T2-4 tumors described in detail in supplementary table 1. Total RNA was isolated, labeled and hybridized to U133A or ExonSt1.0 arrays (Affymetrix, St. Clara USA) as previously described [22,23]. Data were normalized using ArrayAssist version 3.3 (Stratagene, La Jolla CA, USA [25].

\section{RT-qPCR-validation}

It was performed using two sets of samples: "set 1" comprising 18 tumor biopsies (9 Ta and T1, 9 T2-T4) previously analyzed on U133A arrays as well as an independent "set2" with 28 tumor biopsies (10xTa, 8xT1, 10xT2-T4). cDNA was synthesized as previously described [26], using oligo-dT primers. RT-qPCR analysis was performed in triplicates using TaqMan ${ }^{\circledR}$ probe assay TOX3 ID Hs00300355_m1 (Applied Biosystems/Life Technologies, Denmark) as recommended by the manufacturer and analyzed on a 7500 Fast Real-Time PCR system (Applied Biosystems). Results were normalized against UBC as previously described [26]. For STAT1 RT-qPCR we used SYBR green ${ }^{\circledR}$ and primers Stat1 forward 5'-AAGGTGGCAGGATGTCTC-3' and Stat1 reverse 5'-AGGAGGTCATGAAAACGGAT-3'.

\section{Statistical analysis}

It was performed using the STATA 10.0 statistical analysis software (STATA Corporation, College Station, TX, USA).

\section{In situ hybridization (ISH) detection of TOX3}

Five $\mu \mathrm{m}$ sections of a tissue microarray containing $0.6 \mathrm{~mm}$ core biopsies from formalin fixed paraffin embedded (FFPE) tumorswere deparaffinized washing the samples subsequently with Ultraclear (Bie and Berntsen, Denmark), ethanol 100\%, ethanol $70 \%$ and water. Samples were washed in PBS, digested with proteinase $\mathrm{K}(50 \mu \mathrm{g} / \mathrm{ml})$ for $30 \mathrm{~min}$ at RT, fixed $10 \mathrm{~min}$ with $4 \%$ formaldehyde and washed again with PBS. Immediately after, samples were incubated with acetic anhydride/ triethanolamine/water $(2.33 \mathrm{ml}$ triethanolamine, $500 \mu \mathrm{l}$ acetic anhydride, to $200 \mathrm{ml}$ with DEPC (Molecular grade water) for 5 minutes at RT and finally washed with PBS. Slides were pre-hybridized for 3 hours at $55^{\circ} \mathrm{C}$ (perfect match) and $57 \mathrm{C}$ (mismatch) in a humidified chamber with soaked wipes with $50 \%$ formamide and 1 x SSC (Bie and Berntsen). Slides were hybridized with LNA-modified DIG-labeled probes (Exiqon, Vedbaek, Denmark) complementary to the TOX3 transcript, perfect match (5'-AGTCTCATGGTTAAGGGTTTGGGA-3) and mismatch (5'-AGTGTCACGGTCAAGAGTATGGGA-3') overnight at pre-hybridization conditions. Slides were washed and detection was accomplished with anti-DIG antibody and visualized with NBT/ BCIP levamisole solution and finally mounted with Aquatex ${ }^{\circledR}$ aqueous mounting agent (108562, Merck, Germany).

\section{Human bladder cancer cell lines}

T24, SW780, J82,HT1376 and RT4 were obtained from the American Type Culture Collection (ATCC-LGC standards, Borås, Sweden) and were re-authenticated via STR analysis [27] using the Cell-ID-system (G9500, Promega, Nacka, Sweden) within our facilities (http://identicell.dk/identicell-service). Non-malignant transitional epithelial cell lines HCV29 and HU609 were a gift from J. Zeuthen, Denmark. No mycoplasma contamination was detected using nested PCR. COS7 cells (African Green Monkey SV40-transfected kidney fibroblast cell line) were obtained from ATCC.

\section{Immunohistochemistry}

A tissue microarray was stained according to a previously published 
procedure [28]. In brief, after blocking the endogenous peroxidase with hydrogen peroxide for $10 \mathrm{~min}$, the cores were demasked with Heat Induced Epitope Retrieval HIER. Unspecific binding was blocked with $1 \%$ Bovine Serum Albumin (Albumin Fraction V, AppliChem, Germany). The TMA slide was incubated with the primary antibody for $60 \mathrm{~min}$ at room temperature. The DAKO EnVision+ visualization system was used to visualize the antigen through a chromogen reaction. Immunohistochemistry was performed essentially as described by Heebøll et al. [29], using rabbit anti-TOX3 antiserum derived from Anirvan Gosh, UCLA using 1:1000 and 1:2000 dilutions [18]. All TMA slides were scanned using a Hamamatsu Nanozoomer (Hamamatsu Corporation, Hamamatsu City, Japan) scanner and images were scored using VIS software (Visiopharm A/S, Hoersholm, Denmark). The intensity and pattern of the staining of each biopsy on the tissue microarray was scored blinded to clinical outcome by two independent observers and a consensus scoring was obtained (KBD and NF).

\section{siRNA mediated knockdown}

RT4 cells with high TOX3 transcript levels were cultured in McCoy medium $\left(\right.$ GIBCO $^{\circledR}$, Invitrogen, Life Technologies, Nærum, Denmark) complemented with $10 \%$ FCS (Invitrogen) and $1 \%$ penicillinstreptomycin (Invitrogen) at $37^{\circ} \mathrm{C}$ and $5 \% \mathrm{CO}_{2}$. Cells were transfected with an siRNA pool containing four siRNAs targeting the TOX3 transcript (Dharmacon/Thermofisher Scientific, Denmark \# L02255501) or a control scrambled siRNA (Dharmacon \# D-001206-14-20) using Lipofectamine 2000 (Invitrogen) according to the manufacturer's instructions. Final concentrations of $20 \mathrm{nM}$ and $100 \mathrm{nM}$ were used. RNA extraction, cDNA synthesis and RT-qPCR analyses were carried out as described above and expression values were normalized against UBC [26].

\section{Cloning, overexpression and Immunofluorescence micros- copy (IF)}

The 1734 bp TOX3 coding sequence (NM_001080430 was cloned into pcDNA 3.1/V5-His TOPO vector (Invitrogen) using primers sense $5{ }^{\prime}$-CTTCGGCATGGATGTGAGGTTCTA and antisense 3'-GAAAATACTGACCTGCGATAATAC. All DNA sequences were sequence-verified. COS7 cells were cultured in RPMI 1640 medium $\left(\mathrm{GIBCO}^{\circledR}\right.$, Invitrogen), supplemented with $10 \% \mathrm{FCS}$ and $1 \%$ penicillinstreptomycin at $37^{\circ} \mathrm{C}$ and $5 \% \mathrm{CO}_{2}$. Cells were transiently transfected with pcDN3.1 TOX3/V5-His or an empty vector (mock) using FuGene 6 (Roche, Hvidovre, Denmark) following the manufacturer's instructions. T24 human bladder cancer cells were cultured in McCoy's medium $\left(\right.$ GIBCO $^{\circledR}$, Invitrogen) supplemented with $10 \%$ FCS and $1 \%$ pen/strep. Transient transfection of T24 bladder cells with these vectors was achieved using FuGene HD (Roche). For IF studies, cells were fixed and permeabilized with cold methanol $\left(-20^{\circ} \mathrm{C}\right)$ at room temperature, stained with mouse anti V5 antibody $(1 \mu \mathrm{g} / \mathrm{ml}$, ab27671, Abcam, UK) and the secondary antibody goat anti-mouse Alexa ${ }^{\mathbb{B}}$ Fluor 488 (Molecular Probes, Eugene, Oregon (1:2000)). Nuclei were counterstained with 4',6-diamidino-2-phenylindole (DAPI). Cells were mounted with Fluorescent Mounting Medium (DakoCytomation, Denmark). A Zeiss Axiovert $200 \mathrm{M}$ fluorescence microscope and Axiovision software were used for visualization.

\section{Protein extraction, SDS PAGE and western blots}

Whole cell protein extracts from transfected COS7 and T24 cells were prepared and analyzed on $4-12 \%$ gradient gels according to a previously published procedure [30]. The primary antibodies used were rabbit polyclonal anti-TOX3 antiserum raised against rat TOX3 protein [18], a kind gift from Anirvan Ghosh, San Diego, USA used in 1:500 and 1:1000 dilutions, as well as mouse anti-V5 (SV5-Pk1) (ab27671 Abcam, 1:2000), and mouse anti-V5 ChIP-grade (ab15828, Abcam). The goat polyclonal anti TOX3 (ab77432, Abcam) was highly unspecific and could thus not be used for western blots or immunohistochemistry. The secondary antibodies were goat antimouse HRP conjugated (DakoCytomation, 1:3000) and rabbit antigoat HRP conjugated (P0449 Dakocytomation, 1:2000).

\section{Expression profiling of cell extracts}

Total RNA from T24 cells harvested at three time points (16, 20 and 24 hours post-transfection) was purified using RNeasy MinElute columns following the manufacturer's instructions (Qiagen, Copenhagen, Denmark). The RNA quality was analysed on a 2100 Bioanalyzer (Agilent technologies, Hoersholm, Denmark), and samples with a $28 \mathrm{~S} / 18 \mathrm{~S}$ ratio $<1.0$ and RNA integrity number, $\mathrm{RIN}<7$ were excluded. One microgram of total RNA was labeled according to the GeneChip Whole Transcript (WT) Sense Target Labeling Assay and hybridized to Human Exon 1.0 ST Arrays (Affymetrix) and analyzed as previously described [23]. The expression value threshold was arbitrarily set to (background $\log 2<4.0$ ). Data were normalized and a "log 2 ratio" between mock treated and TOX3 over expressing samples was calculated for each time point.

\section{Ingenuity pathway analysis (IPA)}

Microarray expression data normalized with RMA (Robust Multichip Average) were subjected to IPA, 2012. Expression values were normalized around zero and normalized ratios given as (-INF, $-1)$ and $(1,+\mathrm{INF})$ were submitted to IPA (Ingenuity, Redwood City, California, USA).

\section{Cell viability assays}

2000-3000 T24 cells per well were seeded in triplicates in a 96 well microplate and transfected with pcDN3.1 TOX3/V5-His or a mock. Viability was assessed by an MTT-assay(3-(4,5-Dimethylthiazol-2-yl)2,5-diphenyltetrazolium bromide) (Roche) at $24 \mathrm{~h}, 48 \mathrm{~h}, 72 \mathrm{~h}$ and 96 $\mathrm{h}$ post-transfection and absorbance (540/690) was measured. 4000 8000 T24 cells per well were seeded in triplicates and transfected with lipofectamine $2000(0.2 \mu \mathrm{g} /$ well vector, $0.5 \mu \mathrm{l} /$ well lipofectamine 2000 (Invitrogen) in $100 \mu$ total media). The media was exchanged $4 \mathrm{~h}$ after transfection. Cell proliferation was monitored in RealTime using the RTCA xCELLigence SP instrument (Roche).

\section{Immobilized DNA binding assay}

A STAT1 promoter fragment (438 bp) was PCR amplified from genomic DNA previously extracted from T24 cells using Gentra puregene DNA purification kit (Qiagen). The primers used for the PCR reaction were 5'- GGCAATGTCAACTATGAATCCT and 3'CGTCAACTCTGCCCCATGCTT. The PCR fragment was cloned in a TOPO TA cloning kit (Invitrogen) and sequenced. $70 \mu \mathrm{g}$ total protein from cells transfected with TOX3 or a mock was pre-cleaned with $50 \mu \mathrm{l}$ protein $\mathrm{G}$ agarose (Roche). The supernatant was subsequently incubated with $2 \mu \mathrm{g}$ antibody (mouse anti-V5 Abcam). Complexes were incubated with protein $\mathrm{G}$ agarose and the binding assay performed as described [31]. 100 fmol gel-purified STAT1 promoter fragment was incubated 30 minutes at room temperature, washed four times and finally bound DNA was eluted in high salt buffer. DNA was ethanol precipitated and resuspended in $10 \mu \mathrm{l}$ Tris- $\mathrm{HCl} 10 \mathrm{mM} \mathrm{pH} 8.5$ buffer. $1 \mu \mathrm{l}$ of the eluted DNA was run in an Agilent DNA chip on a 2100 Bioanalyzer (Agilent) or used for RT-qPCR with the same primers 
described above using SYBR green and analyzed on a 7500 Fast RealTime PCR system (Applied Biosystems).

\section{Results}

\section{TOX3 expression in non-muscle invasive bladder tumors}

The gene expression profiles of 89 human bladder biopsies comprising 9 normal urothelia, 56 non-muscle invasive Ta and T1 tumors as well as 24 muscle-invasive T2-T4 tumors analyzed on Affymetrix U133A gene chips showed a significant up-regulation of TOX3 expression in $\mathrm{Ta}$ and $\mathrm{T} 1$ tumors compared to normal urothelia $\left(\mathrm{p}<10^{-6}\right)$ or T2-T4 tumors $\left(\mathrm{p}<10^{-4}\right)$ (Figure 1A). RT-qPCR analysis using 16 samples validated the data previously obtained by microarray analysis (Figure 1B). In addition, an independent set of 28 samples comprising Ta, T1 and T2-4 tumors also showed a differential expression of TOX3 between non-muscle invasive and muscle invasive tumors (Figure 1C)

Interestingly, some of the T2-T4 tumors showed relatively high TOX3 $\log 2$ expression intensities (Figure 1D). To identify a potential correlation between TOX3 expression and patient outcome, twenty three of the $24 \mathrm{~T} 2$-T4 tumors from patients with at least 3 years clinical follow-up data and known TOX3 expression status were subjected to statistical analysis. Being aware of the lack of statistical power due to the limited number of samples, preliminary data showed a significant difference $(\mathrm{p}=0.034)$ in terms of survival of patients with T2-4 bladder tumors. Patients with high or moderate TOX3 expression had a better overall survival rate compared to patients with low or no TOX3 expression in the tumor (Figure 1E).

\section{TOX3 expression is tumor specific}

In situ hybridization using LNA (Locked Nucleic Acid) targeting TOX3 was used to show that theTOX3 transcript is specifically expressed in tumor cells. Using a tissue microarray comprising $189 \mathrm{Ta}, 101 \mathrm{~T} 1$ and 34 T2-T4 tumors with $>3$ years detailed follow up showed that the TOX3 transcript was expressed in the nucleus and the cytoplasm of tumor cells (data not shown). Unfortunately, immunohistochemical analyses of the TOX3 protein expression failed, as no specific antibody was available.

\section{TOX3 is localized in the nucleus}

The TOX3 protein has an NLS sequence KRAAPDSGKPKTPKKKKKK between amino acids 231 and 250 [4], predicting a nuclear localization of TOX3. Transient Overexpression of TOX3 in COS7 cells using a vector containing the full-length V5-HIS tagged TOX3 showed a nuclear localization of the TOX3 protein (Figure 2A). T24, SW780 and HT1376 lacking endogenous TOX3 transcript expression were transiently transfected with a mock or the vector encoding the V5-HIS tagged TOX3 fusion protein. However, only T24 bladder cancer cells showed a satisfactorily transfection efficiency where TOX3-V5-HIS protein expression was already detected at $16 \mathrm{~h}$ and was increased upon $24 \mathrm{~h}$ post-transfection (Figure $2 \mathrm{~B}$ ).

The apparent molecular weight of the fusion protein was about $75 \mathrm{kDa}$, being slightly higher than the calculated mass of $68 \mathrm{kDa}$. As no specific commercial anti-TOX3 antibody was available, we used the anti-TOX3 antiserum raised against the rat TOX3 protein to authenticate our recombinant TOX 3 protein. The rat TOX3 protein showed $88 \%$ identity with the human TOX3 protein and Dittmer et al. [14] stated that the rat anti TOX3 serum has a rather low sensitivity [14]. However, Western blotting successfully detected the 75kDa TOX3-V5-
HIS protein over expressed in HEK cell extracts compared to control cells transfected with the empty vector (Figure 2C). Due to the presence of a multitude of unspecific bands, results from immunohistochemical analysis were unfortunately inconclusive.

\section{TOX3 decreased cellular viability}

Analysis of the cellular viability and proliferation by MTT assays showed that proliferation stalled in T24 cells transfected with the TOX3 vector construct suggesting that TOX3 Overexpression had a negative impact on cellular viability and proliferation. In contrast, untreated T24 control cells or T24 cells transfected with an empty vector (mock) showed increased proliferation at 48 hours post-transfection compared to the TOX3 over expressing cells and proliferation proceeded until the experiment was terminated at $96 \mathrm{~h}$ post-transfection (Figure 2D). Real Time Cell analysis (RTCA) using the xCELLigence-system showed that TOX3 Overexpression had an impact on the T24 cells at about nine hours post-transfection (Figure 2E). Cells transfected with an empty vector or a GFP expressing vector continued to proliferate, while proliferation of the TOX3 over expressing T24 cells stalled (Figure 2E). However, microscopic, visual inspection of the T24 cells did not show any signs of apoptosis in terms of nuclear condensation or morphological changes.

\section{TOX3 over-expression affected the interferon signaling pathway}

TOX3 was over-expressed in T24 cells, RNA and protein were extracted and TOX3-V5-His protein expression was monitored by Western blotting (Figure 2B). Whole genome expression profiling was performed using Human Exon 1.0 ST Arrays (Affymetrix) and data from TOX3 over expressing cells were compared to their corresponding mock treated cells at three different points of time at $16 \mathrm{~h}, 20 \mathrm{~h}$ and 24 $\mathrm{h}$ post-transfection. Applying a cutoff level of $\log 2>|0.5|$ at $24 \mathrm{~h}$ post transfection, 1442 transcripts were found to be upregulated, 261 were down regulated. Transcripts differentially expressed and accompanied by $\log 2>|1.0|$ were submitted to Ingenuity Pathway analysis software (IPA). TOX3 Overexpression significantly affected the canonical pathways "Interferon Signaling" ( $p$ value 2.25E-10, 8/34 molecules differentially expressed) depicted in figure $3 \mathrm{~A}$, the activation of IRF by Cytosolic Pattern Recognition Receptors (2,79E-08, 8/63), VDR/RXR Activation $(8,59 \mathrm{E}-05,6 / 79)$ as well as EIF2 signaling $(2.46 \mathrm{E}-04,8 / 182)$. With regard to the cellular functions, TOX3 over-expression affected 45 genes involved in cellular growth and proliferation (2.89E-05) and 38 molecules involved in cell death (4.43E-07).

The majority of the transcripts differentially expressed upon TOX3 Overexpression were found to be upregulated. Transcripts differentially expressed at all three time points accompanied with a log ratio $>|1.0|$ are shown in table 1 . Differential expression was already detectable at $16 \mathrm{~h}$ post-transfection and IFI44L, MX1 and OAS2 were found to be among the genes strongest upregulated at all three time points. Moreover, TOX3 Overexpression in T24 bladder cancer cells resulted in minor up regulation of pro-apoptotic genes, namely CASP6, BNIP3 and $\mathrm{BAD}$ at $24 \mathrm{~h}$ post-transfection (Supplementary table 2 ).

TOX3 Overexpression induced a strong up-regulation of twelve interferon inducible genes, namely STAT1, TAP1, IFITM1, IRF1, IRF9, IFIT1, OAS1, MX1, IFI6, ISG15, IFIT3 and IRF9. Remarkably, exon array data showed that the almost 9-fold up regulation of the TOX3 transcript was accompanied by an approximately 3 -fold up regulation of the STAT1 transcript (Figure 3B). RT-qPCR analysis of the TOX3 and STAT1 transcripts confirmed the strong up regulation of STAT1 upon TOX3 Overexpression in T24 cells (Figure 3C). 
A

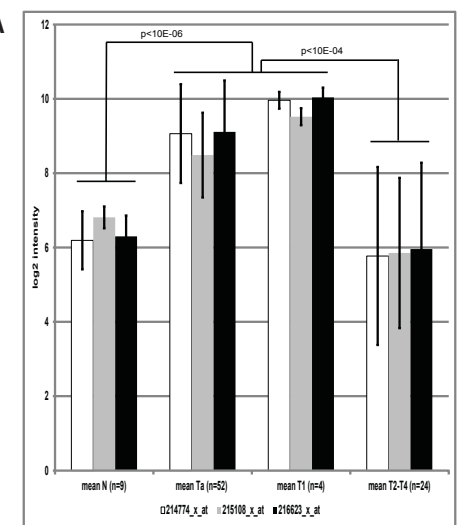

B

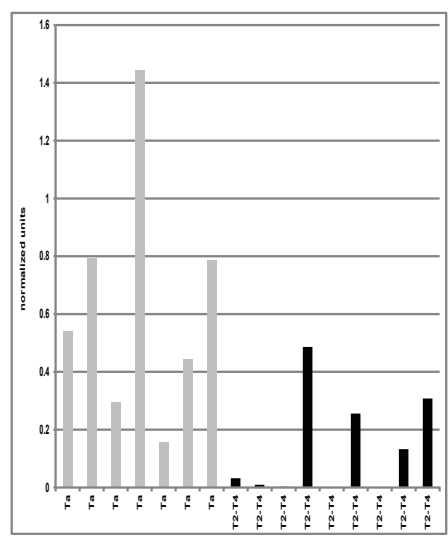

C

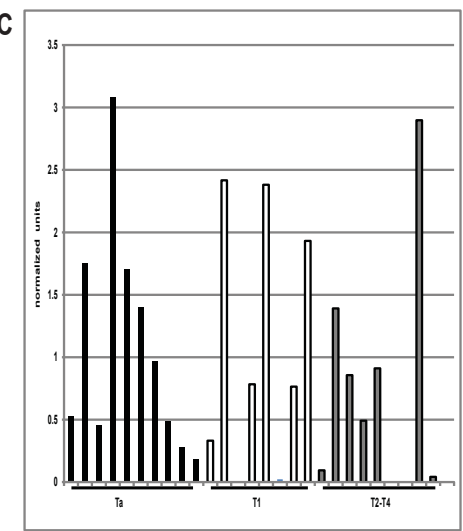

D

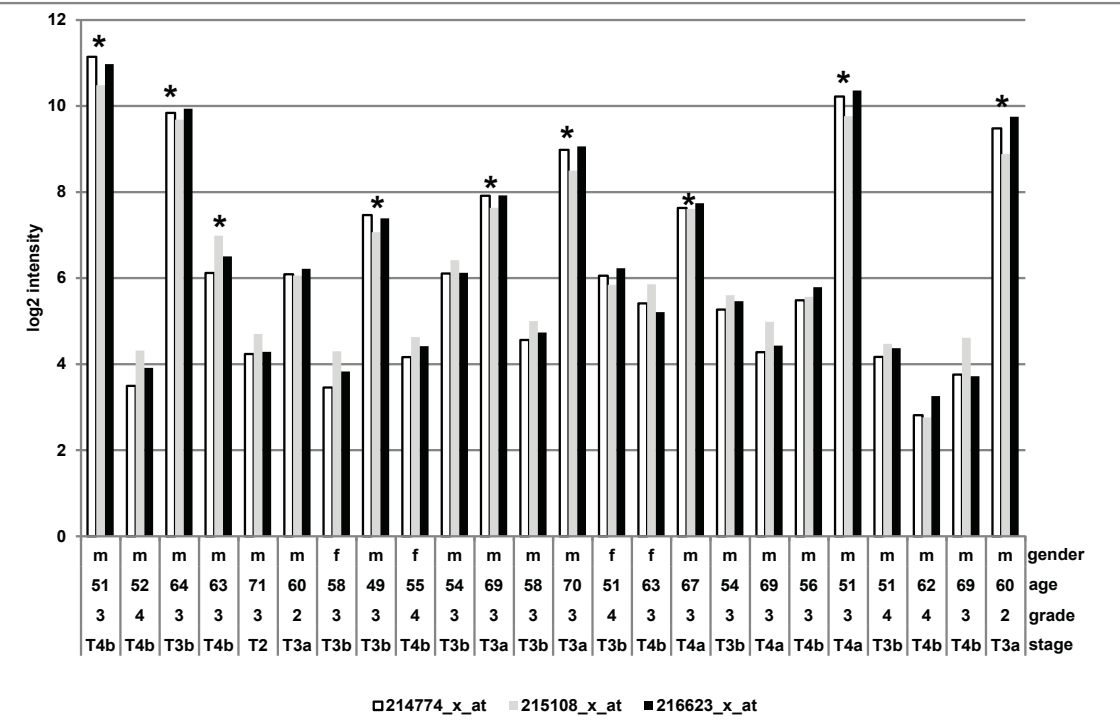

E

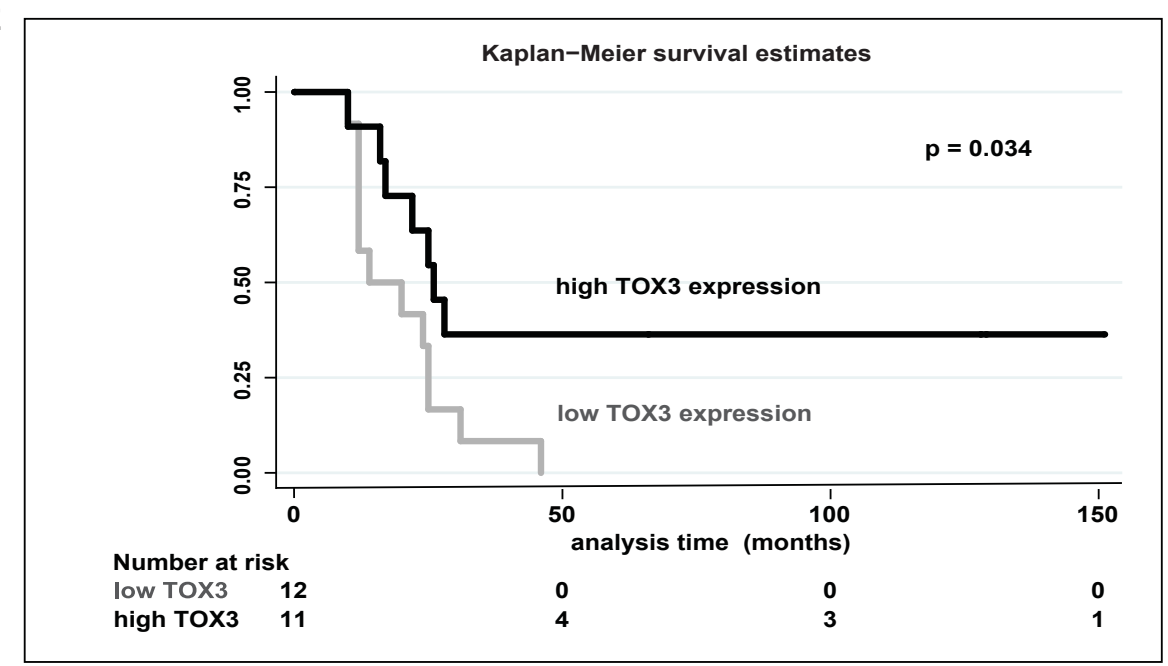

Figure 1: TOX3transcript expression in bladder cancer biopsies. A) Log2 median expression values with standard deviation of normal urothelium ( $n=9$ ), non-muscle invasive $(n=56)$ and muscle-invasive tumors ( $n=24)$ analyzed on U133A microarrays with three different TOX3 probes. B) RT-qPCR analysis of 16 tumors previously analyzed on U133A microarrays confirmed a significant $(\mathrm{p}=0.02)$ upregulation of TOX3 in non-muscle invasive Ta tumors $(\mathrm{n}=7$, median 0.542$)$ compared to muscle invasive T2-4 tumors ( $n=9$, median 0.032). Data were normalized to UBC. C) TOX3 transcript localization in clinical samples assessed by ISH using a tissue microarray showed that the TOX3 transcript localized in the tumor cells. D) TOX3 transcript expression shown as log2 intensities obtained from a panel of 24 T2-T4 tumor samples analyzed on U133A arrays with three probes for TOX3. Samples with high TOX3 expression log2>6 are labeled with an asterisks. E) Kaplan Meier survival estimates on 23 of the 24 T2-T4 samples analyzed on U133A arrays with detailed patient follow up data. Preliminary data showed that patients with T2-4 tumors with high TOX3 levels showed a significant $(\mathrm{p}=0.034)$ better survival compared to those with low or absent TOX 3 expression. 
A

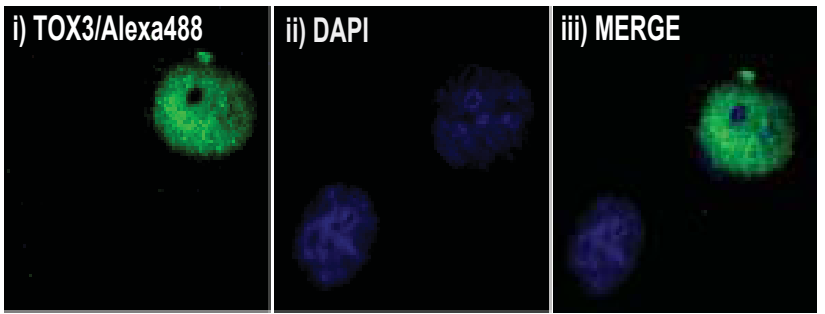

B
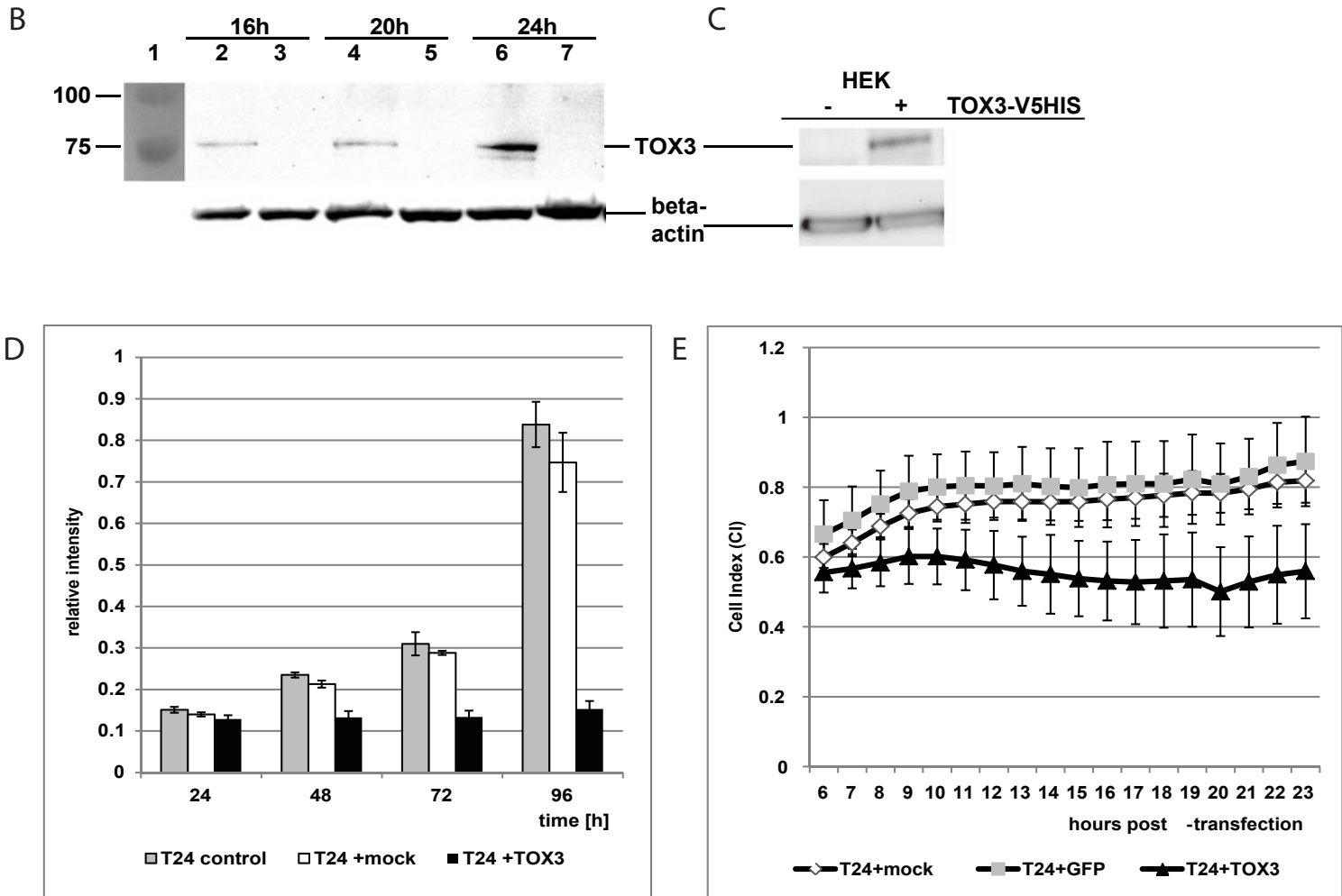

Figure 2: In vitro functional analysis. A) COS7 cells were transiently transfected with the vector pcDN3.1 TOX3/V5-His. i) Cells expressing the TOX3-V5/HIS tagged fusion protein stained green (anti-V5 primary antibody, secondary antibody coupled to Alexa488); ii) DAPI nuclear blue stain; iii) merged, co-localization of the TOX3 protein in the nucleus (magnification 630x, Zeiss Axiovert200M). B) T24 bladder cancer cells were transiently transfected with an empty vector pcDN3.1 V5-His (mock) or pcDN3.1 TOX3/V5-His and whole cell protein extracts from three different time points post-transfection were analyzed by $4-12 \%$ gradient SDS-PAGE. Western blotting followed by incubation with the anti-V5 antibody showed a band with a molecular weight of about $75 \mathrm{kDa}$ for the TOX3-V5/HIS tagged fusion protein. Lane 1 Marker, All Blue BioRad; lane 2,4,6 vector pcDN3.1 TOX3/V5-His, the TOX3-V5/HIS tagged fusion protein was already expressed 16h post-transfection; lane 3, 5, 7 empty vector pcDN3.1 V5-His (mock). C) Extracts from HEK cells over-expressing TOX3-V5/HIS were incubated with the anti-TOX3 antibody from A. Gosh. D) T24 bladder cancer cells were untreated (T24 control) or transiently transfected with an empty vector pcDN3.1 V5-His (T24+mock) or the pcDN3.1 TOX3/V5-His vector (T24+TOX3). Cell viability was accessed by an MTT assaybetween $24 \mathrm{~h}-96 \mathrm{~h}$ post-transfection. Cells over expressing TOX3 (black) stopped proliferation, while control cells (gray) as well as mock transfected cells (white) proliferated further. E) Cellular proliferation was also accessed in RealTime using the RTCA X-Celligence DP or SP instruments (Roche). 3000 T24 bladder cancer cells per well were seeded in triplicates on E-plates and transiently transfected with a vector encoding GFP (green fluorescent protein, T24+GFP) or an empty vector pcDN3.1 V5-His (T24+mock) or the pcDN3.1 TOX3/V5-His vector (T24+TOX3). Cells over expressing TOX3 stopped proliferation, while GFP transfected cells as well as mock transfected cellspreceded proliferation.

\section{TOX3 impacts STAT1 expression}

In light of these findings, we hypothesized that a siRNA-mediated knockdown of TOX3 might result in a decrease of the STAT1 transcript. RT4 bladder cancer cells with very high endogenous levels of TOX3 were transfected with a pool of three siRNAs. Using $20 \mathrm{nM}$ siRNA resulted in a 55\% knockdown efficiency of the TOX3 transcript compared to cells transfected with a scrambled siRNA control as accessed by RT-qPCR analysis (Figure 3D). The 55\% knockdown efficiency was sufficient to decrease the transcript expression of STAT1 by $25-35 \%$.

\section{TOX3 binds to the STAT1 gamma interferon activation sites (GAS)}

The TOX3 amino acid sequence suggested that the protein is a member of a new subfamily of HMG-box proteins, closely related to the sequence-independent type [4]. Our data showed that up regulation of TOX3 increased the STAT1 transcript, while siRNA mediated knockdown of TOX3 decreased the STAT1 expression, suggesting a regulatory mechanism. This potential regulation is depicted schematically in figure 3A, showing part of the interferon pathway. STAT1 contains a gamma interferon activation site (GAS), 


\section{A}

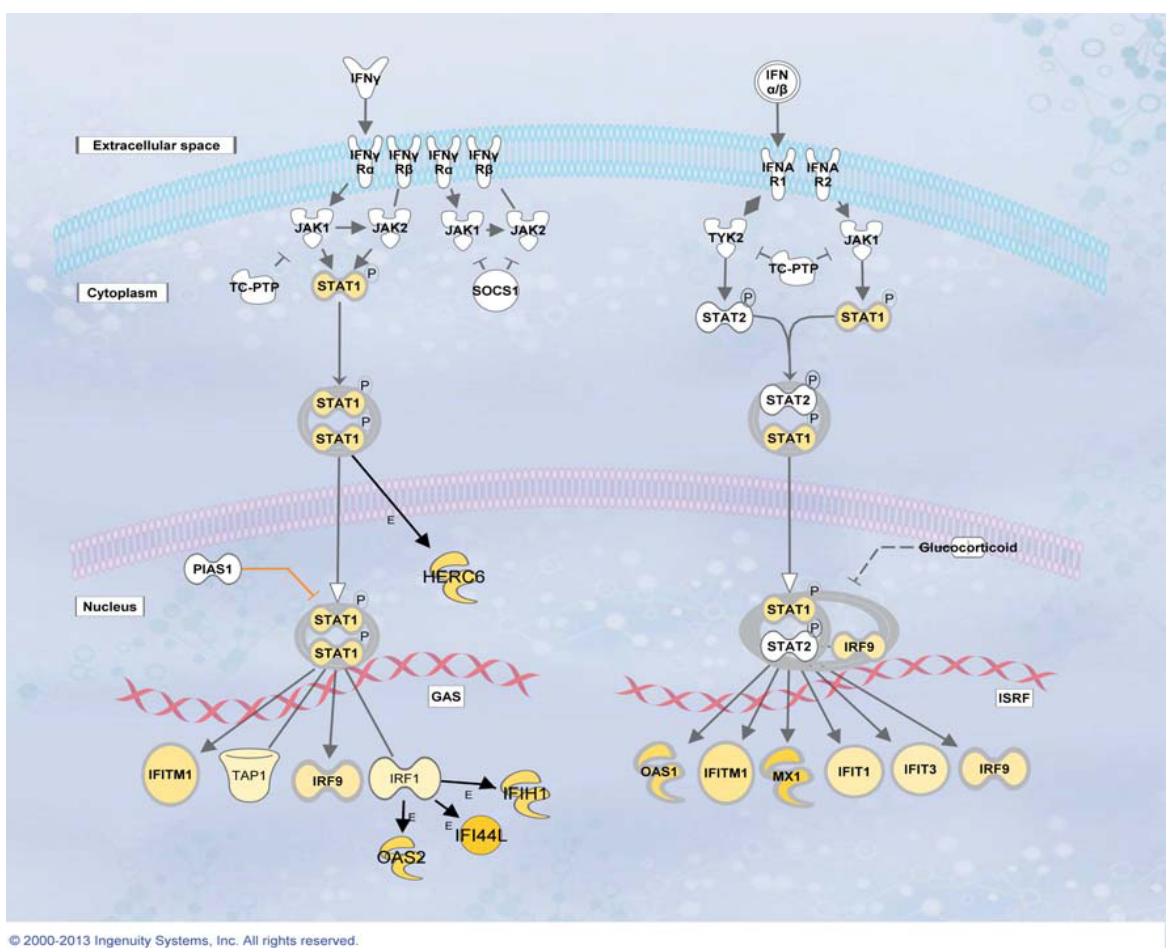

B

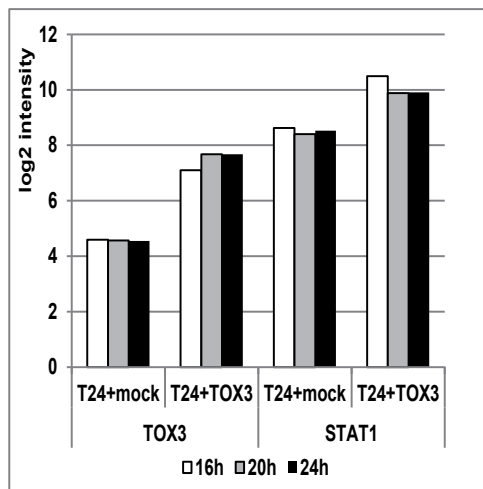

C

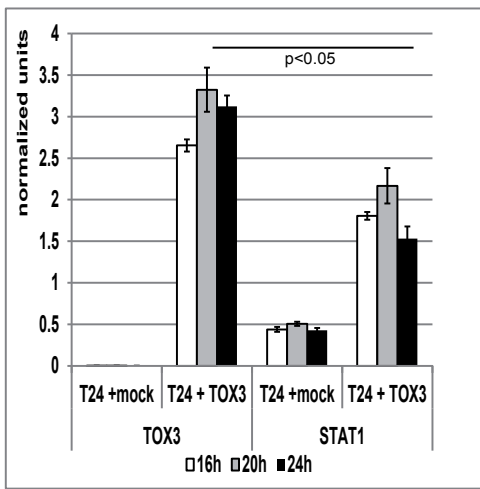

D

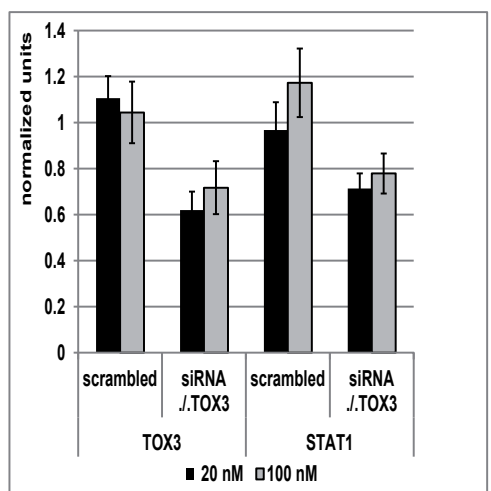

Figure 3: Effect of TOX3 over-expression or siRNA mediated knockdown. A) "Interferon Signaling Pathway". Transcripts upregulated in TOX3 over expressing T24 bladder cancer cells at 16 hours post-transfection are marked yellow (log2 ratio >1 or -1). B) Microarray expression profiling data of mock treated T24 cells or T24 cells over expressing TOX3 (ExonST1.0 arrays, RMA normalized) showed a strong upregulation of TOX3 as well as STAT1 upon TOX3 overexpression. C) RT-qPCR validation of TOX3 and STAT1 expression in mock treated T24 cells or T24 cells over expressing TOX3 confirmed the upregulation identified by microarray profiling on ExonST1.0 arrays. D) siRNA mediated partial knockdown of TOX3 in humanRT4 bladder cancer cells with high endogenous expression applying 20nM or 100nM siRNA resulted in a decrease of the TOX3 transcript compared to the scrambled siRNA used as a control. This downregulation of the TOX3 transcript resulted in a decrease of the STAT1 transcript.

short stretches of DNA, originally defined as a requirement for the rapid transcriptional induction of genes in response to interferongamma (IFN-gamma) [32]. We hypothesized that STAT1 regulation by TOX3 would require the binding of TOX3 to the STAT1 GAS element "TTNCNNNAA". We amplified a DNA-fragment corresponding to the STAT1 proximal promoter containing two GAS sequence targets. Incubation of the GAS DNA element with cell extracts over-expressing TOX3-V5-His and subsequent immunoprecipitation of the complex with the anti-V5 antibody or IgG as a control resulted in an about fourfold enrichment of the GAS containing DNA sequence in the anti-V5 treated samples compared to the IgG treated samples (Figure 4).

\section{Discussion}

TOX3 expression was low in normal urothelium but strongly upregulated in non-muscle invasive compared to muscle-invasive bladder tumors. Overexpression of TOX3 in vitro showed that TOX3 mainly affected the Interferon Signaling Pathway. TOX3 induced the expression of several genes with a GAS site and we showed that TOX3 was able to interact with the GAS-sequence at the STAT1 promoter. siRNA mediated knockdown of TOX 3 in bladder cancer cells decreased STAT1 expression. Immunoprecipitation of TOX3 over expressing cells using an artificial "GAS"-DNA element resulted in an enrichment of the GAS containing DNA-sequence providing evidence for the interaction of TOX3 with the GAS-sequence of STAT1. 
Page 8 of 11

\begin{tabular}{|c|c|c|c|c|c|c|c|c|c|c|}
\hline \multirow[b]{3}{*}{ Transcript Cluster ID } & \multirow[b]{3}{*}{ Gene } & \multicolumn{3}{|c|}{$16 \mathrm{~h}$} & \multicolumn{3}{|c|}{$20 \mathrm{~h}$} & \multicolumn{3}{|c|}{$24 \mathrm{~h}$} \\
\hline & & \multirow{2}{*}{$\begin{array}{l}\text { log2 ratio } \\
\text { TOX3-ctrl }\end{array}$} & \multicolumn{2}{|c|}{$\log 2$ intensity } & \multirow{2}{*}{$\begin{array}{c}\text { log2 ratio } \\
\text { TOX3-ctrl }\end{array}$} & \multicolumn{2}{|c|}{$\log 2$ intensity } & \multirow{2}{*}{$\begin{array}{l}\text { log2 ratio } \\
\text { TOX3-ctrl }\end{array}$} & \multicolumn{2}{|c|}{$\log 2$ intensity } \\
\hline & & & ctrl & TOX3 & & ctrl & TOX3 & & ctrl & TOX3 \\
\hline 2343473 & IFI44L & 4.9 & 3.1 & 7.9 & 3.7 & 3.4 & 7.1 & 3.4 & 3.5 & 6.9 \\
\hline 3922100 & MX1 & 3.9 & 6.1 & 10.0 & 3.9 & 6.0 & 9.9 & 3.7 & 6.1 & 9.7 \\
\hline 3432514 & OAS2 & 3.3 & 6.0 & 9.3 & 3.4 & 5.7 & 9.1 & 3.2 & 5.6 & 8.8 \\
\hline 2584207 & $\mathrm{IFIH} 1$ & 3.0 & 4.3 & 7.3 & 1.2 & 4.5 & 5.7 & 1.6 & 4.5 & 6.0 \\
\hline 3432438 & OAS1 & 3.0 & 6.7 & 9.7 & 2.6 & 6.6 & 9.2 & 2.8 & 6.6 & 9.4 \\
\hline 2792800 & FLJ20035 & 3.0 & 5.0 & 8.0 & 1.9 & 5.1 & 7.0 & 1.9 & 5.3 & 7.1 \\
\hline 2735362 & HERC6 & 2.9 & 6.0 & 8.9 & 1.8 & 6.0 & 7.9 & 1.7 & 6.3 & 8.0 \\
\hline 2692060 & PARP9 & 2.9 & 8.2 & 11.0 & 2.1 & 7.9 & 10.1 & 2.2 & 7.8 & 10.0 \\
\hline 3061438 & SAMD9 & 2.9 & 4.6 & 7.5 & 1.4 & 4.5 & 5.9 & 1.0 & 4.8 & 5.8 \\
\hline 3511698 & EPSTI1 & 2.8 & 5.8 & 8.7 & 2.0 & 5.5 & 7.5 & 2.7 & 5.4 & 8.1 \\
\hline 2403261 & IFI6 & 2.7 & 8.0 & 10.7 & 2.3 & 8.1 & 10.5 & 2.8 & 7.9 & 10.7 \\
\hline 3922037 & MX2 & 2.6 & 6.2 & 8.8 & 2.6 & 5.9 & 8.5 & 2.4 & 6.0 & 8.4 \\
\hline 2639054 & PARP14 & 2.3 & 7.1 & 9.4 & 1.5 & 7.1 & 8.6 & 1.4 & 7.3 & 8.7 \\
\hline 3318443 & TRIM22 & 2.2 & 6.0 & 8.2 & 2.2 & 5.7 & 7.9 & 1.9 & 5.9 & 7.8 \\
\hline 2830861 & EGR1 & 2.2 & 6.7 & 8.9 & 2.5 & 6.0 & 8.5 & 2.7 & 6.4 & 9.1 \\
\hline 2638962 & DTX3L & 2.1 & 6.9 & 9.0 & 1.2 & 7.2 & 8.4 & 1.1 & 7.2 & 8.3 \\
\hline 2571483 & IL1A & 2.0 & 5.6 & 7.6 & 1.7 & 5.1 & 6.8 & 2.6 & 5.3 & 7.9 \\
\hline 3315675 & IFITM1 & 2.0 & 8.1 & 10.1 & 2.6 & 7.5 & 10.1 & 3.1 & 7.5 & 10.6 \\
\hline 2699726 & PLSCR1 & 1.9 & 7.4 & 9.3 & 1.1 & 7.2 & 8.2 & 1.6 & 7.1 & 8.7 \\
\hline 2592268 & STAT1 & 1.9 & 8.6 & 10.5 & 1.5 & 8.4 & 9.9 & 1.4 & 8.5 & 9.9 \\
\hline 3757213 & KRT17 & 1.7 & 8.0 & 9.7 & 1.7 & 7.6 & 9.3 & 2.1 & 7.2 & 9.3 \\
\hline 2608725 & BHLHB2 & 1.7 & 7.2 & 8.9 & 1.2 & 7.2 & 8.4 & 1.2 & 7.1 & 8.4 \\
\hline 3432467 & OAS3 & 1.6 & 7.3 & 8.9 & 1.8 & 7.5 & 9.3 & 1.4 & 7.7 & 9.0 \\
\hline 4000641 & TMEM27 & 1.6 & 2.6 & 4.1 & 1.7 & 2.5 & 4.2 & 1.3 & 2.7 & 3.9 \\
\hline 3529701 & ISGF3G & 1.5 & 7.4 & 8.9 & 1.9 & 6.7 & 8.6 & 2.4 & 6.9 & 9.3 \\
\hline 2489007 & ACTG2 & 1.5 & 5.7 & 7.2 & 1.1 & 5.5 & 6.6 & 1.1 & 5.2 & 6.3 \\
\hline 3203086 & DDX58 & 1.4 & 7.1 & 8.5 & 1.1 & 6.5 & 7.6 & 1.2 & 6.7 & 8.0 \\
\hline 3257246 & IFIT1 & 1.4 & 9.5 & 10.9 & 1.1 & 8.9 & 10.0 & 1.7 & 8.4 & 10.1 \\
\hline 2658595 & HES1 & 1.2 & 7.1 & 8.3 & 1.0 & 7.0 & 8.0 & 1.8 & 6.8 & 8.5 \\
\hline 4053534 & ISG15 & 1.2 & 9.6 & 10.8 & 1.2 & 8.9 & 10.2 & 2.4 & 8.4 & 10.7 \\
\hline 3936550 & USP18 & 1.1 & 7.5 & 8.6 & 1.6 & 7.5 & 9.1 & 1.4 & 7.5 & 8.8 \\
\hline 3223738 & TRAF1 & 1.1 & 5.1 & 6.2 & 1.4 & 5.0 & 6.4 & 2.2 & 4.7 & 6.9 \\
\hline
\end{tabular}

Table 1: Transcript profiling using Exon $1.0 \mathrm{ST}$ array. TOX3 over expressing T24 cells were compared to control cells transfected with an empty vector. Data were RMA normalized and genes with a $\log 2$ ratio $>|1.0|$ at all three time points are shown.

Twelve interferon induced genes (MX1, MX2, PTGS2, IFI6, IFIT1, IFIT2, IFIT4, MTAP44, OAS1, OAS2, IRF7and IL6) were differentially expressed upon TOX3 upregulation. OAS1 and OAS2 are members of the 2-5A synthetase family, they are antiviral, pro apoptotic and antiproliferative. A functional OAS1 polymorphism has been associated with prostate cancer [33]. MX1 and MX2 are members of the dynamin family and the family of large GTPases. MX1, an interferon alpha induced cellular resistance mediator protein being involved in replication, apoptosis, transcription and growth and it has recently been described to be hypermethylated in head and neck squamous cell carcinoma [34]. IFIT2, like IFIT1 and IFIT4 belonging to the IFNinduced proteins with tetratricopeptide repeats, inhibits cell migration in oral squamous cell carcinoma [35]. PTGS2 (COX2) expression is not associated with survival, recurrence, and progression in subgroups (pTa, pT1, pT2-4), while expression of COX2 is common in advanced bladder cancer with poor prognostic characteristics [36].

A previous study, also conducted on T24 bladder cancer cells, showed that the methylation inhibitor 5-Aza-2-deoxycitidine (AZA) is able to trigger a similar interferon response without TOX3 Overexpression [37]. Bender et al. [38] showed that AZA treated T24 cells displayed a suppressed growth rate, probably due to CDKN2A up-regulation [38]. Interestingly, the twelve interferon induced genes differentially expressed upon TOX3 upregulation identified in our study were also found to be upregulated upon AZA treatment [37], suggesting an alternative regulatory mechanism for induction of interferon signaling.

Remarkably, in our study neither EGFR nor interferon, two factors capable of inducing STAT1, were upregulated in the cells and no exogenous growth factors or interferon molecules were added to the medium. In conclusion, in the absence of an extracellular interferon signal, alternative mechanisms seem to be able to trigger an interferonlike response and may lead to cell apoptosis in those cells enabled to undergo controlled cell death.

Based on experiments done in HEK cells, Dittmer et al. [14] suggested an interaction of TOX3 with either CREB or CITED1 in neuronal cells [14]. However, CITED1 does not seem to play a role in bladder cancer due to the fact that CITED1 is not expressed in microarray expression profiled bladder cancer cells previously analyzed (HT1376, HU609, J82, T24, HCV29 and SW780), even not in RT4 cells with very high TOX3 expression levels. Additional experiments are needed to investigate the regulatory mechanism in bladder cancer cells, e.g. the purification of endogenous complexes as well as binding assays with purified proteins, going far beyond the scope of the present study.

Dittmer et al. [14] showed that TOX3 Overexpression in Neuro2a cells protected against tunicamycin-mediated cell death and induced 
A

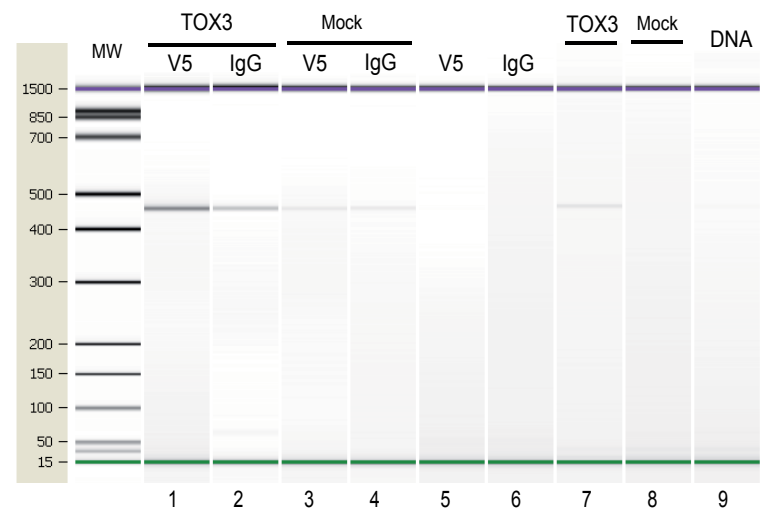

B

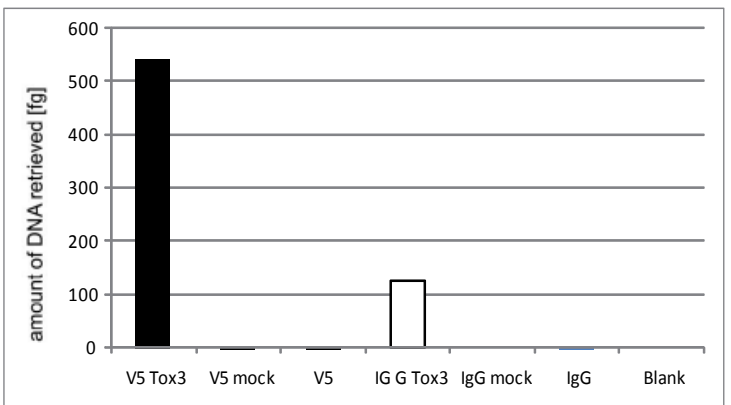

Figure 4: TOX3 binding to a GAS sequence accessed by an Immobilized DNA-binding assay. A) T24 bladder cancer cells were transiently transfected with an empty vector pcDN3.1 V5-His (mock) or the pcDN3.1 TOX3/V5-His vector (TOX3) was incubated with a STAT1 promoter fragment (438 bp). Immunoprecipitation was achieved by either anti-V5 (lanes 1, 3 and 5) or IgG antibodies (lanes 2,4 and 6). A) $1 \mu$ l eluted bound DNA analyzed on an Agilent DNA chip. MW: molecular weight marker (bp size); lane 1,2: cell extracts over expressing TOX3; lane 3,4: cell extracts transfected with a mock, lanes 5, 6 : without cell extract; lane 7 cell extracts over expressing TOX3 but without antibody; lane 8: extracts from mock treated cells without antibody; lane 9 : purified DNA fragment, no cell extract, no antibody. B) RT-qPCR analysis of the samples described in Fig 4A calculated the amount [fg] of DNA retrieved. TOX3 bound to the DNA with the GAS element and in the presence of TOX3 we were able to immunoprecipitate $542 \mathrm{fg} D N A / \mu l$ in the presence of the anti-V5 antibody (black), compared to $125 \mathrm{fg} \mathrm{DNA} / \mu \mathrm{l}$ with the $\mathrm{IgG}$ antibody (white). The control reactions retrieved negligible amounts of DNA.

the expression of anti-apoptotic transcripts in neuronal cells [14]. In contrast to the findings in neuronal cells our microarray data did not show a differential expression of anti-apoptotic transcripts. However, in T24 bladder cancer cells, TOX3 slightly induced some pro-apoptotic genes $24 \mathrm{~h}$ post-transfection. CASP6 is involved in the activation cascade of caspases responsible for apoptosis execution, BNIP3 is an apoptosis-inducing protein which can overcome BCL2 suppression and $\mathrm{BAD}$ promotes cell death and competes for the binding to Bcl$\mathrm{X}(\mathrm{L}), \mathrm{Bcl}-2$ and $\mathrm{Bcl}-\mathrm{W}$ and thus upregulation of these genes may promote programmed cell death. This may suggests a different functional role for TOX3 in bladder cancer compared to neuronal cells being supported by the observed decreased cellular viability of T24 cell upon TOX3 overexpression.

We observed that TOX3 induced genes are mostly acting downstream of STAT1 as depicted in figure 3A. Pathway analysis of TOX 3 over expressing T24 bladder cancer cells at 16 hours posttransfection showed an upregulation of STAT1 and several downstream target genes involved in the canonical "Interferon Signaling pathway".
A very recent article shows that STAT1 promotes pancreatic beta-cell apoptosis [39]. In light of these findings, the activation of STAT1 and thus the interferon signaling pathway could be a possible explanation for the reduced viability of T24 cells seen upon TOX3 upregulation. Unlike the beta-cells, the T24 bladder cells used here have a mutated p53 tumor suppressor gene, preventing them to undergo apoptosis.

The promoter of STAT1 as well as of some of the genes upregulated by TOX3 Overexpression in vitro contained a GAS element. Our data showed that TOX3 was able to bind the GAS element sequence in the STAT1 promoter, suggesting an interaction between TOX3 and the STAT1 GAS element. However, further work will be required to show evidence that the effect is based on a direct sequence specific binding rather than unspecific effects as e.g. DNA bending or other factors driving the transcription.

Based on sequence alignment, TOX3 matched to the DNA sequence-independent HMG-box family [4]. A partial lack of TOX3 specificity for the GAS element would explain the amount of bound DNA recovered in our DNA immobilization assay. Moreover, unspecific DNA binding by TOX3 could also explain why other genes not bearing a GAS sequence were also up-regulated upon TOX3 overexpression in vitro. The GAS sequence is, among others, recognized by STAT1, which is able to activate genes with a GAS element and thus being self-regulated [32]. In conclusion, it is possible that STAT1 is responsible for the up-regulation of genes in the interferon pathway downstream from STAT1 as reported here.

Treatment of bladder cancer with interferon alpha is still in its infancy; however combined therapies look promising. Fishman et al [40] recently reported that a combination of interferon IFN- $\alpha_{2 b}$ and proanthocyanidin GSP may be capable of additively enhancing the anti-proliferative effect on T24 bladder cells [40]. Several attempts have been made where common BCG treatment had been combined with interferon alpha treatment to improve the response rate for BCG treatment of recurrent superficial bladder cancer [41]. In a recent report, altered interferon signaling is pointed out as a key mechanism of immune dysfunction common to all types of cancer [42]. Based on these results the authors hypothesized that in human bladder cancer cells interferon alpha induces TNFSF10 expression and results in apoptosis [43]. This mechanism is triggered via STAT1 and IRF1 and is more sensitive in RT4 cells, a cell line with high levels of TOX3 and mutated CDKN2A. However, the interferon alpha response is cell line dependent, as only a few bladder cell lines have the capability to respond to the signal. The T24 cell line does not respond to interferon alpha induction [44]. TOX3 induction of an interferon-like response does not affect TNFSF10 expression and does not trigger apoptosis even though the expression of STAT1 and IRF1 is up-regulated. Moreover, our expression data showed that TNFSF10 expression remained unchanged comparing $\mathrm{Ta}$ and $\mathrm{T} 1$ versus $\mathrm{T} 2-\mathrm{T} 4$ patients.

\section{Conclusion}

In conclusion, these results suggest an alternative TOX3 activation of the downstream interferon targets, independent of the initial interferon-receptor interaction, and consequently a biological role for TOX3 in bladder cancer. We conclude that TOX3 is a nuclear protein which is differentially expressed in Ta tumors compared to invasive tumors and it induces transcription of genes involved in interferon signaling. This is of utmost interest with regard to the treatment of bladder cancer patients in the future. 


\section{Authors' Contributions}

KBD designed and coordinated the study, designed and performed experiments, interpreted results, drafted the manuscript and made critical revisions of the manuscript.

FM designedandperformedexperiments, interpretedresultsandhelpedtodrafthe manuscript

LDA performed the statistical analysis and helped to draft the manuscript.

KT performed data normalization and analyses of exon-array data

ASBE contributed with array data of tissue samples

NF produced the tissue microarray for ISH and interpreted results

PPM contributed with cDNA synthesis and PCR analyses

KDS contributed to the design and analysis of RT-qPCR experiments/data

TFØ design of the study; helped to draft and correct the manuscript

All authors read and approved the final manuscript.

\section{Acknowledgements}

We are grateful to Susanne Bruun, Pamela Celis, Hanne Steen and Lisbeth Kjeldsen for their excellent technical assistance. We thank Dr. Anirvan Ghosh, UCLA, University of California, San Diego, USA for the generous gift of the antiTOX3 antibody. The work was supported by grants from the John and Birthe Meyer Foundation, the Novo Nordisk foundation, the Lundbeck Foundation, The Danish Cancer Society, Toyota Foundation Denmark, the Danish Research Council and the University and County of Aarhus.

\section{References}

1. Parkin DM, Bray F, Ferlay J, Pisani P (2005) Global cancer statistics, 2002. CA Cancer J Clin 55: 74-108.

2. Dyrskjøt L, Zieger K, Real FX, Malats N, Carrato A, et al. (2007) Gene expression signatures predict outcome in non-muscle-invasive bladde carcinoma: a multicenter validation study. Clin Cancer Res 13: 3545-3551.

3. Aaboe M, Marcussen N, Jensen KM, Thykjaer T, Dyrskjøt L, et al. (2005) Gene expression profiling of noninvasive primary urothelial tumours using microarrays. Br J Cancer 93: 1182-1190.

4. O'Flaherty E, Kaye J (2003) TOX defines a conserved subfamily of HMG-box proteins. BMC Genomics 4: 13

5. Gerber HP, Seipel K, Georgiev O, Höfferer M, Hug M, et al. (1994) Transcriptional activation modulated by homopolymeric glutamine and proline stretches. Science 263: 808-811.

6. Chen MB, Wu XY, Shen W, Wei MX, Li C, et al. (2011) Association between polymorphisms of trinucleotide repeat containing 9 gene and breast cance risk: evidence from 62,005 subjects. Breast Cancer Res Treat 126: 177-183.

7. Liang J, Chen P, Hu Z, Shen H, Wang F, et al. (2010) Genetic variants in trinucleotide repeat-containing 9 (TNRC9) are associated with risk of estrogen receptor positive breast cancer in a Chinese population. Breast Cancer Res Treat 124: 237-241.

8. Ruiz-Narváez EA, Rosenberg L, Cozier YC, Cupples LA, Adams-Campbell LL, et al. (2010) Polymorphisms in the TOX3/LOC643714 locus and risk of breast cancer in African-American women. Cancer Epidemiol Biomarkers Prev 19 $1320-1327$.

9. Han W, Woo JH, Yu JH, Lee MJ, Moon HG, et al. (2011) Common genetic variants associated with breast cancer in Korean women and differential susceptibility according to intrinsic subtype. Cancer Epidemiol Biomarkers Prev 20: 793-798.

10. Easton DF, Pooley KA, Dunning AM, Pharoah PD, Thompson D, et al. (2007) Genome-wide association study identifies novel breast cancer susceptibility loci. Nature 447: 1087-1093.

11. Stacey SN, Manolescu A, Sulem P, Rafnar T, Gudmundsson J, et al. (2007) Common variants on chromosomes $2 \mathrm{q} 35$ and $16 \mathrm{q} 12$ confer susceptibility to estrogen receptor-positive breast cancer. Nat Genet 39: 865-869.

12. Woolcott CG, Maskarinec G, Haiman CA, Verheus M, Pagano IS, et al. (2009) Association between breast cancer susceptibility loci and mammographic density: the Multiethnic Cohort. Breast Cancer Res 11: R10.

13. Li L, Zhou X, Huang Z, Liu Z, Song M, et al. (2009) TNRC9/LOC643714 polymorphisms are not associated with breast cancer risk in Chinese women. Eur J Cancer Prev 18: 285-290.

14. Dittmer S, Kovacs Z, Yuan SH, Siszler G, Kögl M, et al. (2011) TOX3 is neuronal survival factor that induces transcription depending on the presence of CITED1 or phosphorylated CREB in the transcriptionally active complex. $J$ Cell Sci 124: 252-260.

15. Nordgard SH, Johansen FE, Alnaes GI, Naume B, Børresen-Dale AL, et al (2007) Genes harbouring susceptibility SNPs are differentially expressed in the breast cancer subtypes. Breast Cancer Res 9: 113

16. Xi L, Feber A, Gupta V, Wu M, Bergemann AD, et al. (2008) Whole genome exon arrays identify differential expression of alternatively spliced, cancerrelated genes in lung cancer. Nucleic Acids Res 36: 6535-6547.

17. Tessema M, Yingling CM, Grimes MJ, Thomas CL, Liu Y, et al. (2012) Differential epigenetic regulation of TOX subfamily high mobility group box genes in lung and breast cancers. PLoS One 7: e34850.

18. Yuan SH, Qiu Z, Ghosh A (2009) TOX3 regulates calcium-dependen transcription in neurons. Proc Natl Acad Sci U S A 106: 2909-2914.

19. Dittmer S, Sahin M, Pantlen A, Saxena A, Toutzaris D, et al. (2008) The constitutively active orphan G-protein-coupled receptor GPR39 protects from cell death by increasing secretion of pigment epithelium-derived growth factor J Biol Chem 283: 7074-7081.

20. Smith SC, Baras AS, Dancik G, Ru Y, Ding KF, et al. (2011) A 20-gene mode for molecular nodal staging of bladder cancer: development and prospective assessment. Lancet Oncol 12: 137-143.

21. Als AB, Dyrskjøt L, von der Maase H, Koed K, Mansilla F, et al. (2007) Emmprin and survivin predict response and survival following cisplatin-containing chemotherapy in patients with advanced bladder cancer. Clin Cancer Res 13 4407-4414.

22. Dyrskjøt L, Thykjaer T, Kruhøffer M, Jensen JL, Marcussen N, et al. (2003) Identifying distinct classes of bladder carcinoma using microarrays. Nat Genet 33: $90-96$.

23. Thorsen K, Sørensen KD, Brems-Eskildsen AS, Modin C, Gaustadnes M et al. (2008) Alternative splicing in colon, bladder, and prostate cancer identified by exon array analysis. Mol Cell Proteomics 7: 1214-1224

24. Ebele JN, Sauter G, Epstein JI, Sesterhenn IA (2004) World Health Organization classification of tumours: pathology and genetics of tumours of the urinary system and male genital organs. Lyon: IARC Press.

25. Bolstad BM, Irizarry RA, Astrand M, Speed TP (2003) A comparison of normalization methods for high density oligonucleotide array data based on variance and bias. Bioinformatics 19: 185-193.

26. Andersen CL, Jensen JL, Ørntoft TF (2004) Normalization of real-time quantitative reverse transcription-PCR data: a model-based variance estimation approach to identify genes suited for normalization, applied to bladder and colon cancer data sets. Cancer Res 64: 5245-5250.

27. Masters JR, Thomson JA, Daly-Burns B, Reid YA, Dirks WG, et al. (2001) Short tandem repeat profiling provides an international reference standard for human cell lines. Proc Natl Acad Sci U S A 98: 8012-8017.

28. Fristrup N, Ulhøi BP, Birkenkamp-Demtröder K, Mansilla F, Sanchez-Carbayo $M$, et al. (2012) Cathepsin E, maspin, Plk1, and survivin are promising prognostic protein markers for progression in non-muscle invasive bladder cancer. Am J Pathol 180: 1824-1834.

29. Heebøll S, Borre M, Ottosen PD, Andersen CL, Mansilla F, et al. (2008) SMARCC1 expression is upregulated in prostate cancer and positively correlated with tumour recurrence and dedifferentiation. Histol Histopathol 23 1069-1076.

30. Mansilla F, Birkenkamp-Demtroder K, Kruhøffer M, Sørensen FB, Andersen $\mathrm{CL}$, et al. (2007) Differential expression of DHHC9 in microsatellite stable and instable human colorectal cancer subgroups. Br J Cancer 96: 1896-1903.

31. Kim JH (2004) Immobilized DNA-binding assay, an approach for in vitro DNA binding assay. Anal Biochem 334: 401-402.

32. Decker T, Kovarik P, Meinke A (1997) GAS elements: a few nucleotides with major impact on cytokine-induced gene expression. J Interferon Cytokine Res 17: $121-134$

33. Mandal S, Abebe F, Chaudhary J (2011) 2'-5' oligoadenylate synthetase 1 polymorphism is associated with prostate cancer. Cancer 117: 5509-5518.

34. Calmon MF, Rodrigues RV, Kaneto CM, Moura RP, Silva SD, et al. (2009) Epigenetic silencing of CRABP2 and MX1 in head and neck tumors. Neoplasia 11: 1329-1339. 
Citation: Birkenkamp-Demtroder K, Mansilla F, Dyrskjøt L, Thorsen K, Fristrup N, et al. (2013) TOX3 (TNRC9) Overexpression in Bladder Cancer Cells Decreases Cellular Proliferation and Triggers an Interferon-Like Response. J Mol Biomark Diagn 4: 140. doi:10.4172/2155-9929.1000140

Page 11 of 11

35. Lai KC, Chang KW, Liu CJ, Kao SY, Lee TC (2008) IFN-induced protein with tetratricopeptide repeats 2 inhibits migration activity and increases survival of oral squamous cell carcinoma. Mol Cancer Res 6: 1431-1439.

36. Wild PJ, Kunz-Schughart LA, Stoehr R, Burger M, Blaszyk H, et al. (2005) High-throughput tissue microarray analysis of COX2 expression in urinary bladder cancer. Int J Oncol 27: 385-391.

37. Liang G, Gonzales FA, Jones PA, Orntoft TF, Thykjaer T (2002) Analysis of gene induction in human fibroblasts and bladder cancer cells exposed to the methylation inhibitor 5-aza-2'-deoxycytidine. Cancer Res 62: 961-966.

38. Bender CM, Pao MM, Jones PA (1998) Inhibition of DNA methylation by 5-aza2 '-deoxycytidine suppresses the growth of human tumor cell lines. Cancer Res 58: 95-101.

39. Moore F, Naamane N, Colli ML, Bouckenooghe T, Ortis F, et al. (2011) STAT1 is a master regulator of pancreatic \{beta\}-cell apoptosis and islet inflammation. J Biol Chem 286: 929-941.

40. Fishman Al, Johnson B, Alexander B, Won J, Choudhury M, et al. (2012)
Additively enhanced antiproliferative effect of interferon combined with proanthocyanidin on bladder cancer cells. J Cancer 3: 107-112.

41. Nepple KG, Lightfoot AJ, Rosevear HM, O’Donnell MA, Lamm DL, et al. (2010) Bacillus Calmette-Guerin with or without interferon $a \pm 2 b$ and megadose versus recommended daily allowance vitamins during induction and maintenance intravesical treatment of nonmuscle invasive bladder cancer. J Urol 184: 19151919.

42. Critchley-Thorne RJ, Simons DL, Yan N, Miyahira AK, Dirbas FM, et al. (2009) Impaired interferon signaling is a common immune defect in human cancer. Proc Natl Acad Sci U S A 106: 9010-9015

43. Papageorgiou A, Lashinger L, Millikan R, Grossman HB, Benedict W, et al. (2004) Role of tumor necrosis factor-related apoptosis-inducing ligand in interferon-induced apoptosis in human bladder cancer cells. Cancer Res 64 8973-8979.

44. Papageorgiou A, Dinney CP, McConkey DJ (2007) Interferon-alpha induces TRAIL expression and cell death via an IRF-1-dependent mechanism in human bladder cancer cells. Cancer Biol Ther 6: 872-879. 